\title{
Improving the Coastal Mean Dynamic Topography by Geodetic Combination of Tide Gauge and Satellite Altimetry
}

Andersen, Ole Baltazar; Nielsen, Karina; Knudsen, Per; Hughes, Chris W.; Bingham, Rory; FenoglioMarc, Luciana; Gravelle, Médéric; Kern, Michael; Polo, Sara Padilla

Published in:

Marine Geodesy

Link to article, DOI:

$10.1080 / 01490419.2018 .1530320$

Publication date:

2018

Document Version

Peer reviewed version

Link back to DTU Orbit

Citation (APA):

Andersen, O. B., Nielsen, K., Knudsen, P., Hughes, C. W., Bingham, R., Fenoglio-Marc, L., Gravelle, M., Kern, M., \& Polo, S. P. (2018). Improving the Coastal Mean Dynamic Topography by Geodetic Combination of Tide Gauge and Satellite Altimetry. Marine Geodesy, 41(6), 517-545.

https://doi.org/10.1080/01490419.2018.1530320

\section{General rights}

Copyright and moral rights for the publications made accessible in the public portal are retained by the authors and/or other copyright owners and it is a condition of accessing publications that users recognise and abide by the legal requirements associated with these rights.

- Users may download and print one copy of any publication from the public portal for the purpose of private study or research.

- You may not further distribute the material or use it for any profit-making activity or commercial gain

- You may freely distribute the URL identifying the publication in the public portal 


\section{Improving the Coastal Mean Dynamic Topography by Geodetic}

\section{Combination of Tide Gauge and Satellite Altimetry}

Ole B. Andersen ${ }^{1}$, Karina Nielsen ${ }^{1}$, Per Knudsen ${ }^{1}$, Chris W. Hughes ${ }^{2,3}$

Rory Bingham ${ }^{4}$, Luciana Fenoglio-Marc ${ }^{5}$, Médéric Gravelle ${ }^{6}$, Michael Kern ${ }^{7}$, Sara Padilla Polo ${ }^{8}$

(1) Technical University of Denmark, DTU Space, 2800 Lyngby, Denmark.

(2) University of Liverpool, Liverpool, UK

(3) National Oceanography Centre, Liverpool. UK

(4) University of Bristol, Bristol, UK

(5) University of Bonn, Bonn, Germany,

(6) LIENSs, Université de La Rochelle-CNRS, La Rochelle, France

(7) ESA ESTEC Noordwijk, The Netherlands.

(8) LEGOS, CNRS-CNES-IRD-UPS, Toulouse, France

Corresponding author: Ole B. Andersen, DTU Denmark, Elektrovej bldg. 328, DK2800 Kongens Lyngby, oa@space.dtu.dk 


\begin{abstract}
The ocean mean dynamic topography (MDT) is the surface representation of the ocean circulation. The MDT may be determined by the ocean approach, which involves temporal averaging of numerical ocean circulation model information, or by the geodetic approach, wherein the MDT is derived using the ellipsoidal height of the mean sea surface (MSS), or mean sea level (MSL) minus the geoid as the geoid. The ellipsoidal height of the MSS might be estimated either by satellite or coastal tide gauges by connecting the tide gauge datum to the Earth-centered reference frame.

In this paper we present a novel approach to improve the coastal MDT, where the solution is based on both satellite altimetry and tide gauge data using new set of 302 tide gauges with ellipsoidal heights through the SONEL network.

The approach was evaluated for the Northeast Atlantic coast where a dense network of GNSS-surveyed tide gauges is available. The typical misfit between tide gauge and satellite or oceanographic MDT was found to be around $9 \mathrm{~cm}$. This misfit was found to be mainly due to small scale geoid errors. Similarly we found, that a single tide gauge places only weak constraints on the coastal dynamic topography.
\end{abstract}

Keywords: mean dynamic topography, tide gauge, satellite altimetry

\title{
Introduction
}

The ocean's mean dynamic topography (MDT) is the surface representation of ocean circulation. It is of interest to oceanographers to study the ocean's surface currents (Wunsch and Stammer 1997), and to geodesists for e.g. linking height datums globally, particularly in regions where geodetic land-ties (connection by levelling to the land vertical datum) through GNSS measured tide gauges are not possible (Woodworth et al. 2013, Featherstone and Filmer 2012)

The ocean MDT may be determined by the oceanographic approach or the geodetic approach (Huang, 2017; Woodworth et al. 2013). The oceanographic approach involves the use of an ocean circulation models and the MDT is computed through temporal averaging over a given period. 
The geodetic approach involves either satellite derived ellipsoidal mean sea surface models (MSS) (Andersen and Knudsen, 2009) or mean sea level (MSL) observations from tide gauges expressed as ellipsoidal heights from co-located GNSS observations.

Figure 1 illustrates the way that the MSS or MSL is determined using geodetic methods like satellite altimetry and tide gauges. Once referenced to the same reference ellipsoid MSS and MSL represent the same "quantity", but in the following we have used the terminology MSL for individual point observations (from tide gauges) and MSS for satellite derived grids.

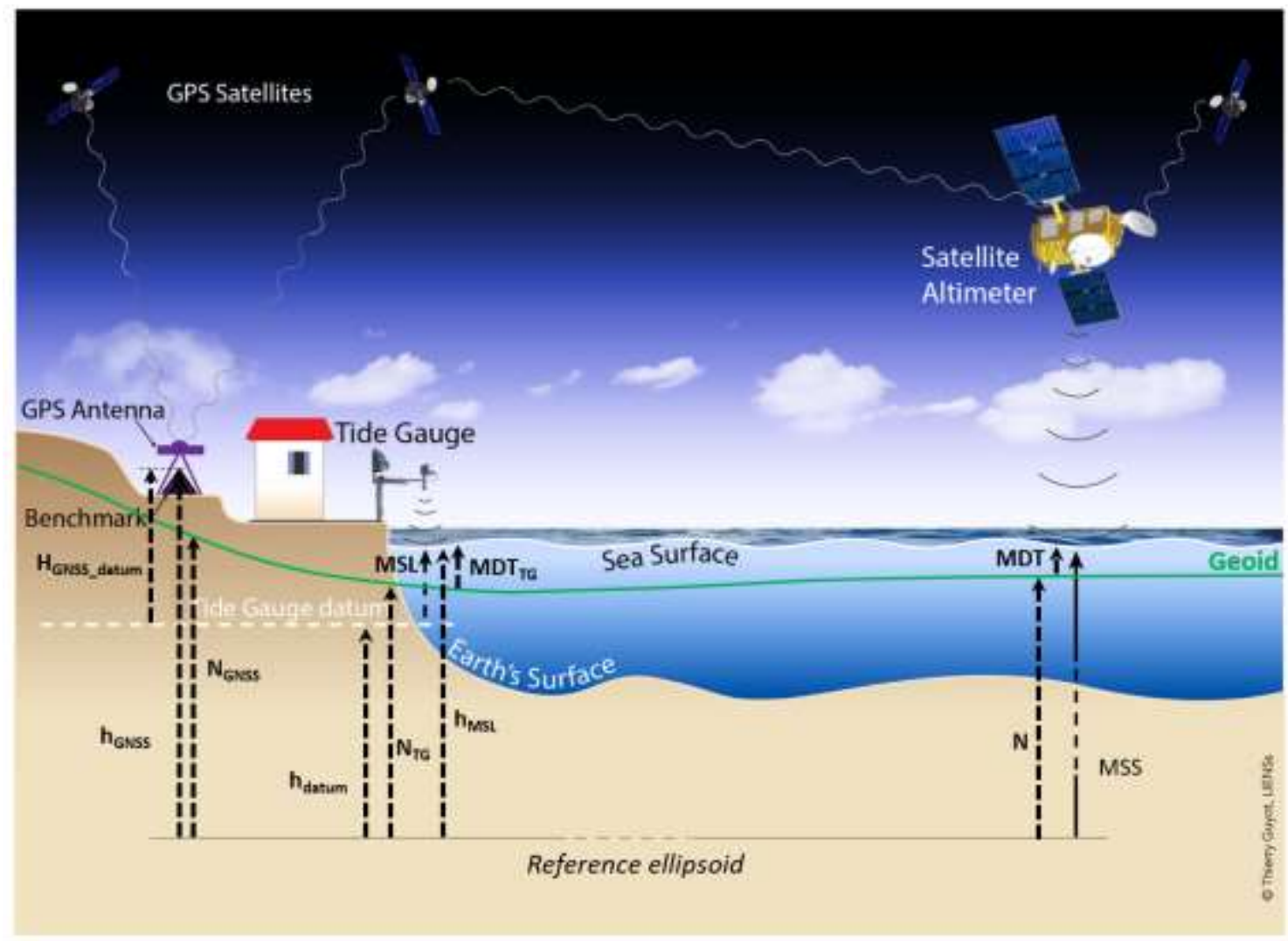

Figure 1: Satellite and tide gauge observations of the ellipsoidal Mean Sea Surface (MSS) or Mean sea level (MSL) relative to the tide gauge datum. The geoid height is called (N); the figure shows the terms of the equations derived in section 2.3. The figure is modified from Thierry Guyot (LIENSs).

From the ellipsoidal MSS or MSL data the MDT can be derived through a purely geometrical approach based on the simple equation

$$
\text { MDT=MSS-N }
$$

The MSS and/or MSL and geoid (N) must be given relative to same tide system and with respect to the same reference ellipsoid. We used the mean tide system and the TOPEX ellipsoid, with a semi major axis of 6,378,136.3 $\mathrm{m}$ and an inverse flattening of 298.257. Other ellipsoids or tide systems can be used through transformation. GNSS 
measurements, that are initially consistent with the WGS84 reference frame, are usually aligned with the International Terrestrial Reference Frame (ITRF) for Earth science applications that require a high degree of accuracy (IERS, 2010). Thus, the GNSS ellipsoidal heights were here transformed to the most up-to-date ITRF realization at the time of the study (the ITRF08 (Altamimi et. al, 2011), which is associated with the GRS80 ellipsoid). In comparison or integration with satellite derived MDT these height are then converted to be consistent with the TOPEX ellipsoid and the mean-tide system following (Ekman, 1989)

This work continues the attempt to improve the coastal mean dynamic topography supporting ESA effort in the use of geoid information for height system unifications and connections (Gruber et al., 2012; Gerlach and Rummel, 2013; Amjardiparvar et al., 2013; Rummel 2012). New and more accurate geoid information is applied from the ESA mission Gravity field and Ocean Circulation Explorer (GOCE) made available via the international center for global Earth Models (IGCEM, http://icgem.gfzpotsdam.de/home). We test a novel approach to derive an improved coastal MDT along the Northeast European coast using a geodetic combination of a satellite MDT at sea combined with a number of tide gauges derived MDT values along the coast. In the following, we refer to this combined geodetic approach as the GOCE++ approach as the work describes the result of the GOCE++ study initiated by the European Space Agency (ESA).

We chose a common five-year period 2003-2007 inclusive for this investigation for consistency. The period was chosen as it offered the highest number of nearuninterrupted tide gauges with ellipsoidal height from GNSS. Out MDT will consequentlyrepresent this period. higher Initially, data and methods are described along with the way the MDT is determined geodetically from satellite and from tide gauges. For the chosen time period we then present the updated set of 302 tide gauges with known ellipsoidal heights from the GNSS data assembly centre for the Global Sea Level Observing System at the Système d'Observation du Niveau des Eaux Littorales (SONEL, http://www.sonel.org). Here we evaluate the degree to which the point measurements of MDT at tide gauges can be reconciled with the broader scale MDTs of ocean models and those derived from altimetry.

Subsequently we present an attempt to merge satellite MDT and tide gauge MDT using an iterative method called GOCE++. The northeast European shelf has a huge number 
of tide gauges including 100 ellipsoidal tide gauges in the SONEL network. This enables us to perform a comparison of the effect on including tide gauges in the coastal MDT solution.

Currently, Synthetic Aperture Radar (SAR) altimetry is becoming available with Cryosat-2 and Sentinel-3 to improve the mapping of the short scales in the MSS. These data are an important step to improve future coastal MDT models and we present an evaluation of the MDT and improvements in the southern North Sea.

\section{Data and methods}

In the following sub-sections, we introduce the various datasets and methods to derive the MDT. We introduce the oceanographic MDT used for comparison as well as the satellite tide gauge data and the way geodetic MDT is computed.

\subsection{Ocean MDT}

Seven ocean models were available for computation of MDT in the study. These are three Nemo (Nucleus for European Modelling of the Ocean) ORCA (Madec, 2008) model integrations, one at a resolution of $1 / 4^{\circ}(\mathrm{NemoQ})$, and two at a resolution of $1 / 12^{\circ}$ with slightly different versions of the model code (Nemo12a, Nemo12b). Two Liverpool University implementations of the Massachusetts Institute of Technology (MIT) global ocean circulation model (Marshall et al., 1997a, 1997b), assimilating hydrographic information provided by the UK Met Office (Smith and Murphy, 2007); one in a coarse form ( $\mathrm{LivC})$, with a global resolution of $1^{\circ}$ and a finer version (LivS) with an increased resolution of $1 / 5^{\circ} \times 1 / 6^{\circ}$ in the North Atlantic. The final two models are products of the ECCO consortium to calculate ocean state estimates by assimilating a wide variety of data, including geodetic data. EccoG (ECCO-Godae) has a global resolution of $1^{\circ}$ (Köhl et al., 2007) producing a model state and evolution which is perfectly consistent with the model equations. Ecco2 (Menemenlis et al., 2005a; 2005b) is a finer resolution model (specified as approximately $18 \mathrm{~km}$, but supplied on a 0.25 degree grid), with a looser assimilation scheme designed to match only certain patterns within the observations. All ocean models incorporate climatology for their initiation, as well as wind and atmospheric forcing from meteorological re-analyses. All models are averaged over the chosen period of 2003-2007 inclusive. 


\subsection{Satellite MDT.}

Computing the satellite MDT is conceptually simple with the use of Eq.1. However, there are several complications in computing the satellite MDT. The major complication is the fact, that the geoid is typically given with limited resolution (typically hundreds of kilometers) compared to the MSS (tens of kilometers).

Subtracting a geoid $\mathrm{N}$ given in spherical harmonic coefficients up to a certain degree and order L the resulting dynamic topography estimate,

$$
\mathrm{MDT}_{\mathrm{R}}=\mathrm{MDT}+\Delta \mathrm{NL},
$$

where the derived $\mathrm{MDT}_{\mathrm{R}}$ consists of the MDT plus an un-modelled part of the geoid of spherical harmonic degrees and orders higher than L appearing as an omission error due to spherical harmonic coefficients which are omitted in the geoid model. This error decreases with increasing degree and order L of the geoid. The GOCE satellite has been paramount to reduce the geoid error in global geoids where the degree and order of satellite only GOCE geoids is typically around 250.

Consequently, a filter needs to be derived and applied to Eq. 2 to eliminate the $\Delta \mathrm{NL}$ without removing real MDT signal in the filtering. It is naturally important to design appropriate linear or non-linear filters for this operation (Bingham and Haines, 2006; Bingham et al., 2011; Sanchez-Reales et al, 2016).

We decided to use the alternative approach to limit the omission error $\Delta \mathrm{NL}$ by using a geoid and a MSS given at the same resolution. We used the European Improved Gravity model of the Earth by New techniques (EIGEN) combined 6C4 geoid to degree and order 2190 due to consistency with the MSS. This EIGEN6C4 geoid (Förste 2014) consists of a combination of GRACE and GOCE up to degree and order 260 augmented with the DTU10 surface gravity data. For the investigation, we used the DTU10MSS (Andersen and Knudsen, 2009; Andersen et al., 2016). This is computed as an average of satellite altimetry over the period 1993-2009, but is mapped to the 2003-2007 average by using the difference in AVISO (Archiving, Validation, and Interpretation of Satellite Oceanographic data) absolute dynamic topography (ADT) averages over the two periods. DTU10MSS was preferred because this model is consistent with various geoids like the EIGEN6C4 and the TUM13 (Fecher et al., 2015) geoid (the gravity anomaly dataset is derived from the DTU10MSS, so the difference does not add artificial small-scale errors into the dynamic topography). 
Altimetric MSS is corrected for the ocean's inverted barometer (IB) response (static atmospheric loading effect) using Wunsch and Stammer (1997) and a correction for periods shorter than the sampling of the Topex and Jason satellite via the Dynamic Atmosphere Correction. This correction is applied, as it reduces the sea surface variability leading to a more stable estimation of the mean. In our approach, we decided to restore the effect of the atmosphere on the sea surface to be consistent with the tide gauge mean.

The total error of the satellite derived MDT will be a combination of the geoid omission errors along with errors in both the MSS and the geoid coefficients (commission errors). The satellite MDT is typically less accurate in the coastal zone due to a combination of less accurate altimetric observations, less accurate geoid mapping due to large bathymetry/topography variations and the fact that the MDT changes more rapidly in the coastal zone.

\subsection{Tide gauge MDT}

Using global tide gauges for comparisons and combination with satellite MDT implies that the tide gauges height is linked into a Earth-centered global reference frame using GNSS measurements at the local tide gauges transforming the observations to ellipsoidal heights. This link usually relies on two quantities: the GNSS-derived ellipsoidal height of a tide gauge benchmark in the global reference ( $\mathrm{h}_{\mathrm{GNSS}}$ in Figure 1), obtained from the processing of permanent or episodic GNSS measurements, and the height of this benchmark with respect to the tide gauge datum ( $\mathrm{H}_{\mathrm{GNSS} \_d a t u m}$ in Figure 1$)$. The latter is always known f from the Permanent Service for Mean Sea Level (PSMSL) (Holgate et al, 2013) When the benchmark height is not available, a supplemental measurement is needed to connect this benchmark to one where GNSS ellipsoidal height is known (mostly using spirit leveling). This is commonly called a geodetic tie (Woodworth et. al, 2017), and ultimately yields A in Figure 1.

\subsubsection{Tide gauges with permanent GNSS.}

The use of GNSS for monitoring the tide gauge sites stability is optimized when it is processed continuously and globally (Wöppelmann and Marcos, 2016). Thus, the availability of positions and vertical velocity of tide gauge co-located permanent GNSS 
stations was a priority for the investigation. The geodetic ties of 113 RLR tide gauges with nearby permanent GNSS stations were collected from the SONEL data assembly centre (http://www.sonel.org). Fourteen additional ties were recovered for the German tide gauges, which are not in the RLR dataset yet (http://pegelonline.wsv.de). For most of these permanent GNSS stations, the ellipsoidal height (associated to an epoch and an uncertainty) was extracted from the last GPS solution (ULR6a) of the ULR analysis centre provided on SONEL (Santamaria et. al, 2017). The vertical velocities were then used to propagate the ellipsoidal height from the reference epoch to the average epoch of the selected period 2003-2007 (2005.5). For permanent stations, that were not included in this solution, the ellipsoidal heights were obtained from the average of three positions per day, processed using the Canadian CSRS-PPP tool (https://webapp.geod.nrcan.gc.ca/geod/tools-outils/ppp.php), also expressed in the ITRF08 reference frame. For the ULR6 stations that did not satisfy the "robust" velocity criteria defined by SONEL, the propagation to the epoch 2005.5 could not be performed and the stations were rejected.

\subsubsection{Tide Gauges with episodic measurements.}

Ellipsoidal heights from GNSS campaigns at tide gauge sites were retrieved from different sources; mostly via Woodworth et. al (2013), Woodworth et. al (2015), Featherstone \& Filmer (2012), Lin et al (2015) and SONEL, and led to 189 additional RLR ellipsoidal heights.

For most of the ellipsoidal heights coming from episodic GNSS measurements, the epoch and the uncertainty is unknown. This is a source of error, and it was not possible to propagate the heights to the mean epochs of the selected period (they were adopted as is, as for permanent GNSS stations without enough data to obtain a robust velocity and the heights coming from the CSRS-PPP tool). These stations were associated with a $\mathrm{cm}$ uncertainty (arbitrary based on our personal experience).

\subsubsection{Computing the mean sea level}

For the RLR stations, the monthly time series from PSMSL were used to compute the MSL over the 2003-2007 period. For records with more than $70 \%$ of data over this period, a classic average was calculated. For the remainder 54 stations we applied simultaneous observations from satellite altimetry data to fill the gap. This was done in 
three stages: first, a least squares fit of IB-corrected tide gauge data on an annual cycle, semiannual cycle, linear trend, and altimeter time series was computed for every altimeter point (using the AVISO gridded dynamic topography, www.aviso.altimetry.fr/en) within $150 \mathrm{~km}$ of the tide gauge. Second, the altimeter point for which the resulting fit explained the largest percentage variance of the tide gauge data was selected, and tide gauge data predicted from that least squares fit for every month. Third, the predicted tide gauge time series was used to fill gaps in the tide gauge data, with an additional linear trend added over each gap to ensure the bestfit the end points. This yield a dataset of 302 ellipsoidal MSL values for the 2003-2007 period globally distributed (Error! Reference source not found.).

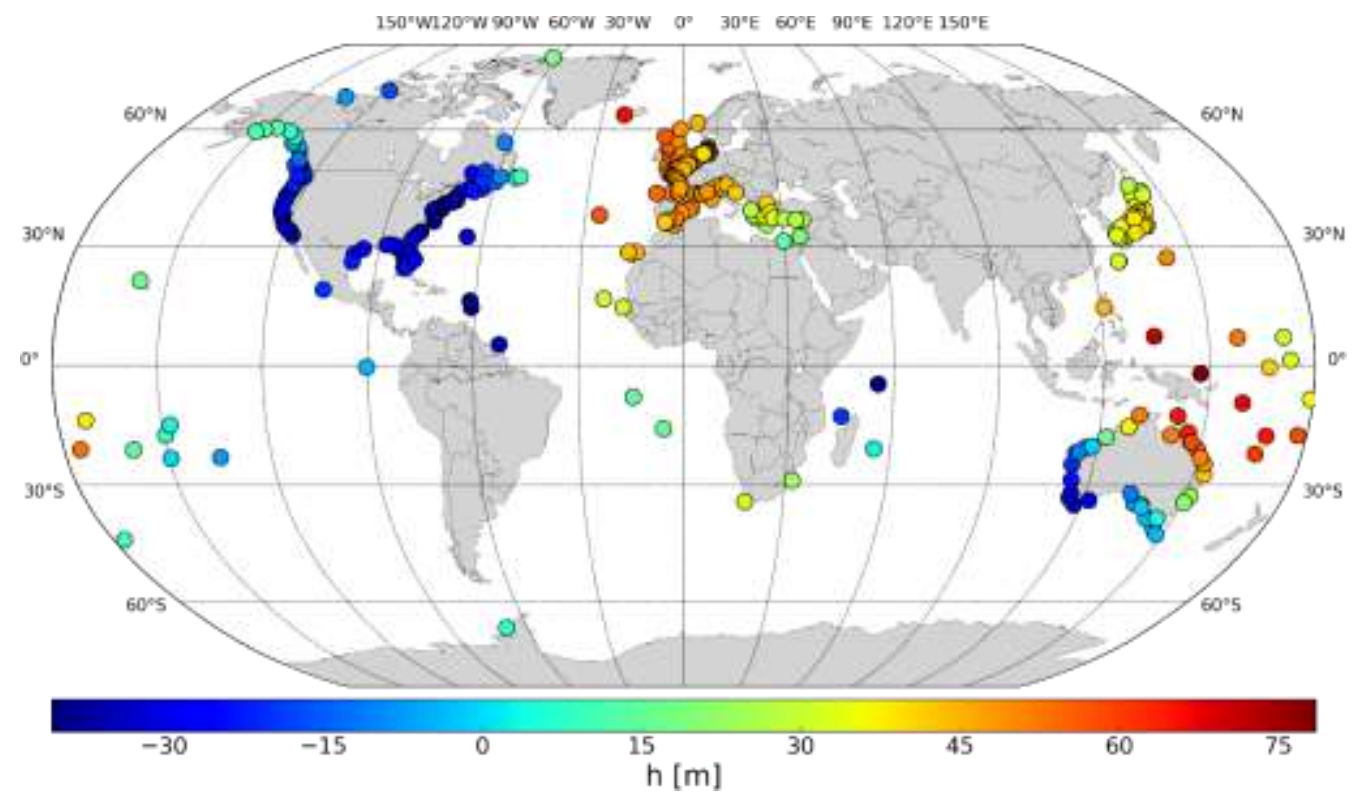

Figure 2: Ellipsoidal Mean sea level at tide gauges over (2003-2007)

Following Equation 1, the MDT computation at a tide gauge implies subtracting the geoid height from the ellipsoidal MSL. Thus, at a tide gauge site, Equation 1 can be written as follows (Figure 1):

$$
M D T_{T G}=h_{M S L}-N_{T G}
$$

where $M D T_{T G}$ is the MDT value at the tide gauge, $h_{M S L}$ is the tide gauge ellipsoidal MSL and $N_{T G}$ is the geoid value at the tide gauge. $h_{M S L}$ can be developed as follows:

$$
h_{M S L}=h_{\text {datum }}+M S L
$$

where $h_{\text {datum }}$ is the ellipsoidal height of the datum of the tide gauge measurements and $M S L$ value as observed by the tide gauge with respect to this datum.

$h_{\text {datum }}$ is obtained by adding the ellipsoidal height of the nearby GNSS station $\left(h_{G N S S}\right)$ and the ellipsoidal height difference between the points $\left(D H_{d a t-g n s s}\right)$ : 


$$
h_{\text {datum }}=h_{G N S S}+D H_{\text {dat-gnss }}
$$

$D H_{\text {dat-gnss }}$ is equal to the geodetic tie used (tie $e_{\text {dat-gnss }}$ ) only if it comes from differential GNSS (and the tie is geometric and expresses indeed a difference of ellipsoidal heights). If the geodetic tie comes from spirit leveling, it expresses a difference in elevations and the geoid gradient has to be taken into account:

$$
D H_{\text {dat-gnss }}=t i e_{\text {dat-gnss }}+N_{T G}-N_{G N S S}(6)
$$

where $t i e_{\text {dat-gnss }}$ is the geodetic tie used. Here it comes from spirit leveling and $N_{G N S S}$ is the geoid value at the tide gauge-co-located GNSS point from which the tie has been derived. At the end, Equation (3) becomes:

$$
M D T_{T G}=h_{G N S S}+\text { tie }_{\text {dat-gnss }}+M S L-N_{T G}
$$

if the $t i e_{d a t-g n s s}$ is a difference of ellipsoidal heights, and:

$$
M D T_{T G}=h_{G N S S}+t i e_{d a t-g n s s}+M S L-N_{G N S S}
$$

if tie dat-gnss is a difference of elevations. Note that Equation (7) and Equation (8) are the same if the GNSS point is very close (few meters) to the tide gauge (in that case, the geoid heights at the tide gauge $\left(\mathrm{N}_{\mathrm{TG}}\right)$ and at the GNSS $\left(\mathrm{N}_{\mathrm{GNSS}}\right)$ are equal).

Computing the MDT values at the tide gauges from the ellipsoidal MSL implies identifying the type of the geodetic tie in order to determine whether the geoid value has to be extracted at the tide gauge position or at the co-located GNSS point. We assumed that the GNSS point was situated in the vicinity of the tide gauge for episodic GNSS point and that the geoid difference between the locations is negligible.

For some countries the tide gauges benchmark (if available) are not linked to the national vertical datum. For such this suggested unification is particularly important to establish a height system and enables such links.

For tide gauges with permanent GNSS stations, the geodetic ties were explicitly accounted for, but for episodic GNSS it was assumed (for lack of any other information) that no tie was necessary. In strong geoid gradients areas, the impact could reach more than ten centimeters (Figure 13). The importance of the geoid extraction point indicates the equal importance of the correct position of the tide gauge: particular care has been taken to check the coordinates of the 302 selected tide gauges. 


\section{Evaluation and representativeness of tide gauge MDT}

The tide gauge measurements with geocentric position information discussed above have been converted to MDT estimates by subtracting a geoid from the MSS thus defined, i.e. by applying equation (7) or (8) as appropriate. Here we evaluate the degree to which the point measurements of MDT at tide gauges can be reconciled with the broader scale MDTs of ocean models and those derived from altimetry, considering the effect of different geoids and different truncations. Note that, for this comparison with models (most of which do not include atmospheric pressure as a forcing), we again apply the IB correction to all MDTs derived from tide gauges or altimetry.

As the global mean value of MDT from ocean models is ill-defined, we subtract this off from all mapped products. To do this in a consistent way given the different spatial domains of the different products, we first choose a reference model with global coverage (Ecco2) and subtract off the global mean MDT from this model. For other mapped products, we subtract off the spatial average of the difference from the demeaned Ecco2, over their common domain. For comparisons purely at tide gauge positions below, we further subtract the median of differences from the tide gauge MDT across all available sites, so statistics relate to the spatial variations in MDT and not the absolute values.

In addition to the Aviso MDT, we also use a second altimeter-derived MDT labelled here TUM13, which is formed from the DTU2010 MSS minus the TUM13 geoid. This was smoothed with a spatially-varying Wiener filter chosen using a signal size estimate from the Nemo12a ocean model and noise based on the assumption that variations in a known smooth region of the Pacific are all noise. The same product was also used in Filmer et al. (2018).

The ordering of the tide gauges follows the PSMSL coastal ordering. This starts with Norway, running anticlockwise around Europe, Africa and Asia, then covers Australia and the Pacific, before running anticlockwise around the Americas starting with Alaska and ending with Arctic Canada, before finally moving to Antarctica (the last point only). See Appendix 1 for more detail. 


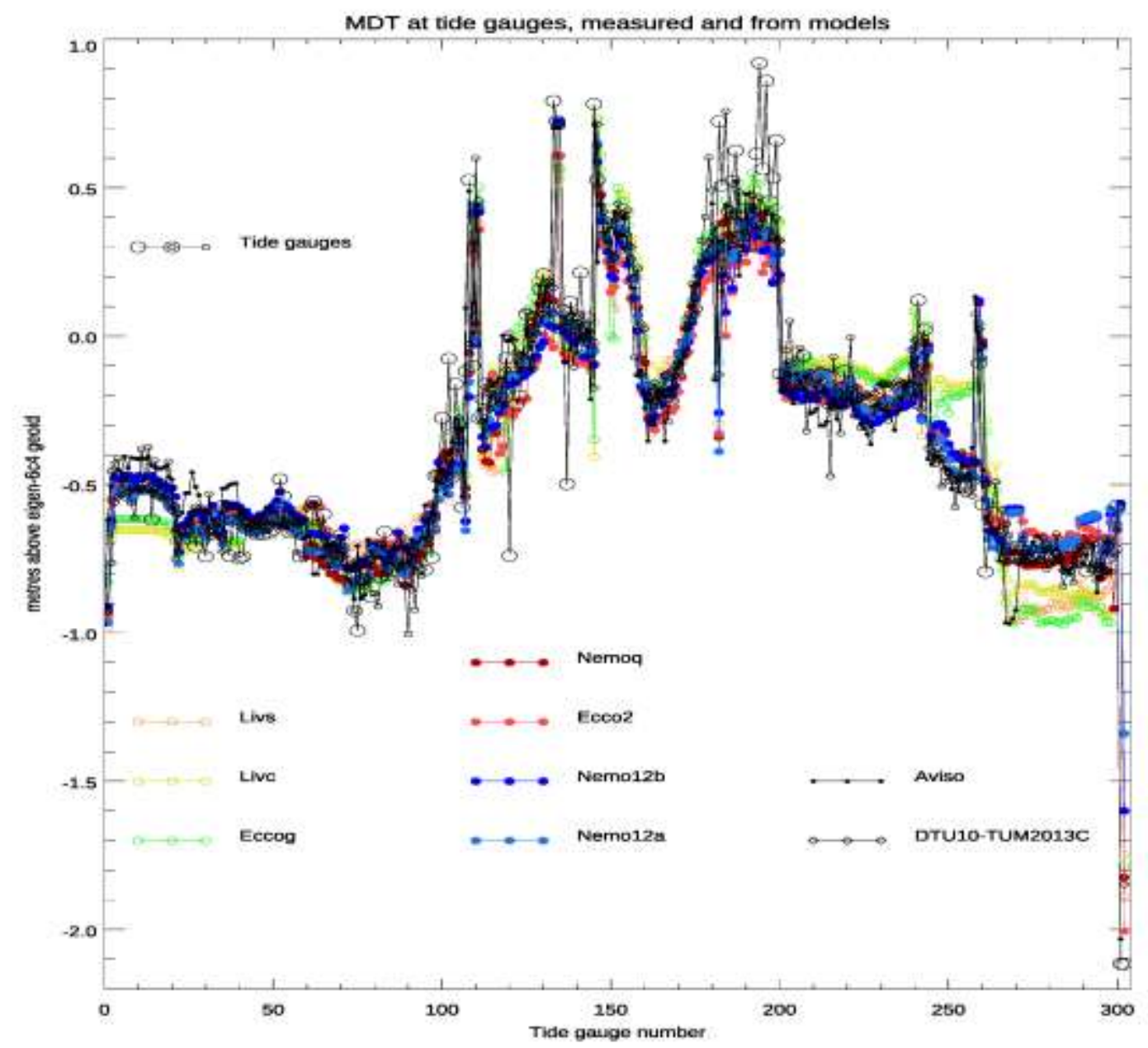

Figure 3: The MDT at 302 tide gauges (black open circles) using the EIGEN-6C4 geoid to its full resolution, compared with predictions from 7 ocean models (colours), and 2 satellite-derived MDTs (black). Large open circles represent sites with continuous GNSS, and small open circles those with episodic GNSS. Continuous GNSS, but an estimated MSL/MSS error of $>0.04 \mathrm{~m}$ is shown as a double circle (5 sites).

Several considerations can be made immediately from Figure 3. The match is generally good, but the tide gauges show a systematic high bias between about numbers 182 and 200, corresponding to the Pacific Islands. The two prominent downward spikes (121 and 138) are Aburatsubo (near Tokyo) and Mikuni (fairly nearby, but on the opposite, north coast of mainland Japan). Tectonic activity is an obvious concern, but the many other Japanese records look good. Other "spikes" are common to tide gauges and models, and represent excursions off the main coastline to islands. 
Table 1 shows summary statistics based on these comparisons. The distribution is clearly non-Gaussian, with long tails and a more compact central region, leading to a high excess kurtosis (kurtosis-3; a Gaussian distribution has an excess kurtosis of zero, https://www.itl.nist.gov/div898/handbook/eda/section3/eda35b.htm). We see that the global MDTs which produce the worst comparisons tend to have lower kurtosis, becoming closer to Gaussian values. This provokes a tentative interpretation, that the global MDT errors tend to be more Gaussian, and the errors at tide gauges include more extreme values, probably due to missing fine-scale geoid information. This will be investigated in more detail below.

Table 1: Statistics comparing the coastal MDT at tide gauges estimated using the EIGEN-6C4 geoid to full resolution, against 8 different global MDTs extrapolated to the same positions. Height values are in metres. The pdfs are non-Gaussian, so they are characterized by half the range which contains the number of values which would be expected to fall within 1 sigma in a Gaussian distribution (1 sigma equiv), or quarter the range for 2 sigma. Also given are the minimum and maximum values (TG-MDT after subtracting the median), and the number of missing values (because some MDTs do not have data in some regions). Where there are no missing values, there are 302 points being compared.

\begin{tabular}{|l|l|l|l|l|l|l|l|l|l|}
\hline $\begin{array}{l}\text { Global } \\
\text { MDT }\end{array}$ & Std & 1 sigma & $\begin{array}{l}2 \\
\text { sigma }\end{array}$ & Min & Max & $\begin{array}{l}\text { Skew } \\
\text { ness }\end{array}$ & $\begin{array}{l}\text { Excess } \\
\text { Kurtosi } \\
\text { s }\end{array}$ & $\begin{array}{l}\text { N } \\
\text { mis } \\
\text { sing }\end{array}$ & $\begin{array}{l}\text { err } ~ \\
9 \mathrm{~cm}\end{array}$ \\
\hline Nemo12a & 0.132 & 0.097 & 0.142 & -0.775 & 0.571 & -0.33 & 7.69 & 0 & 67 \\
\hline NemoQ & 0.123 & 0.095 & 0.127 & -0.588 & 0.617 & +0.43 & 5.41 & 0 & 68 \\
\hline Aviso & 0.134 & 0.099 & 0.131 & -0.727 & 0.556 & -0.21 & 6.27 & 3 & 65 \\
\hline $\begin{array}{l}\text { DTU10TUM1 } \\
3\end{array}$ & 0.131 & 0.109 & 0.139 & -0.726 & 0.589 & +0.10 & 4.47 & 4 & 62 \\
\hline Nemo12b & 0.139 & 0.101 & 0.157 & -0.586 & 0.633 & +0.60 & 4.45 & 0 & 64 \\
\hline Ecco2 & 0.145 & 0.121 & 0.153 & -0.471 & 0.706 & +0.99 & 3.18 & 1 & 54 \\
\hline Livs & 0.161 & 0.132 & 0.177 & -0.632 & 0.753 & +0.75 & 3.24 & 3 & 54 \\
\hline EccoG & 0.158 & 0.150 & 0.159 & -0.600 & 0.540 & -0.14 & 0.63 & 7 & 40 \\
\hline Livc & 0.163 & 0.153 & 0.169 & -0.572 & 0.546 & -0.05 & 0.62 & 7 & 42 \\
\hline
\end{tabular}

It is clear, that the data are able to discriminate between models, especially when ignoring the tails of the distributions. By far the most important factor is the quality of the geoid, and in particular its fine scale structure corresponding to limiting the omission error in Eq 2. This is similar to what was seen by Huang (2017). This is illustrated by Figure 4, which repeats Figure 3 but with the EIGEN6-C4 geoid truncated 
at degree 300 roughly corresponding to the degree and order of a satellite only geoid from GOCE.

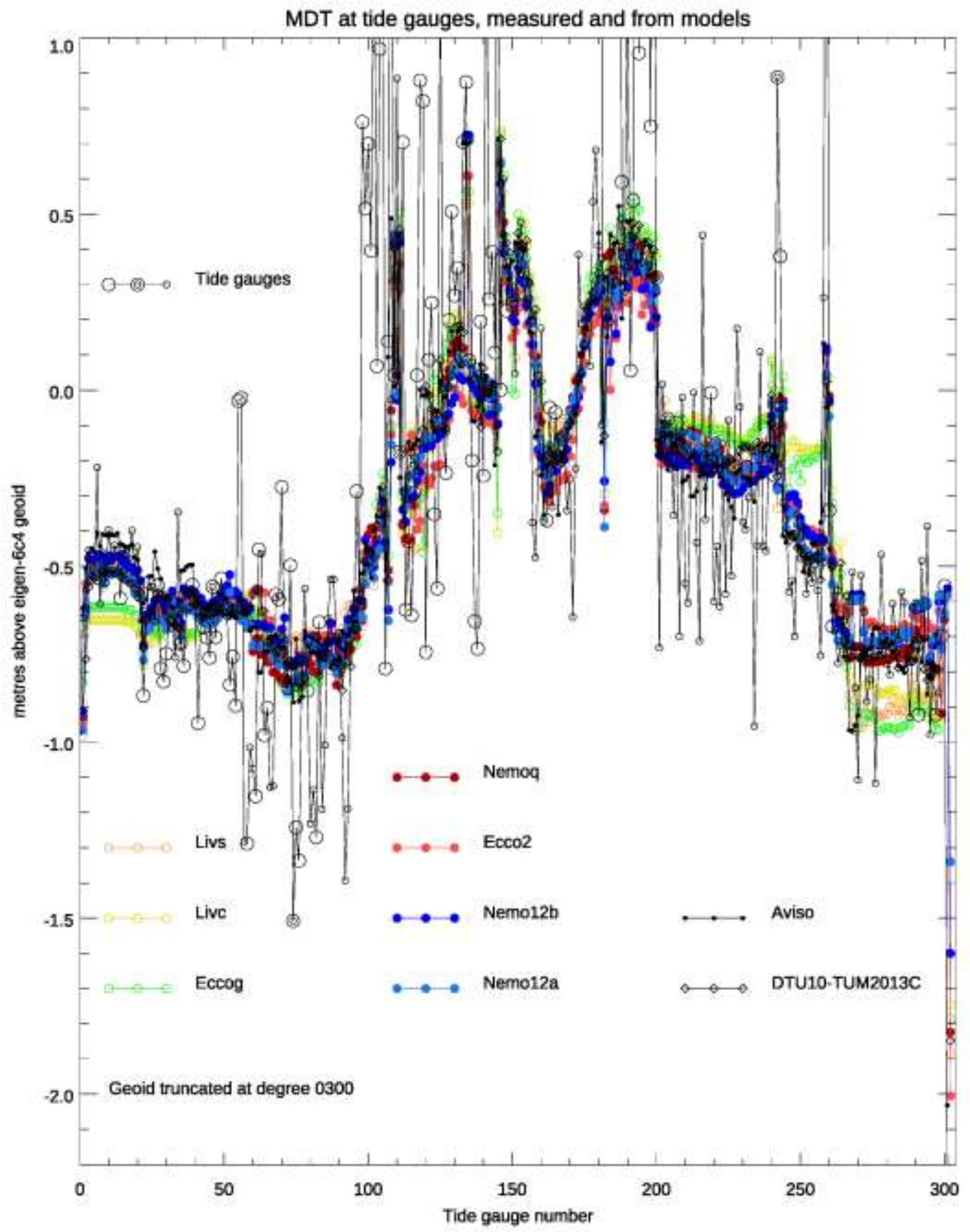

Figure 4: repeat of Figure 3 but with the EIGEN-6c4 geoid truncated at degree 300. 


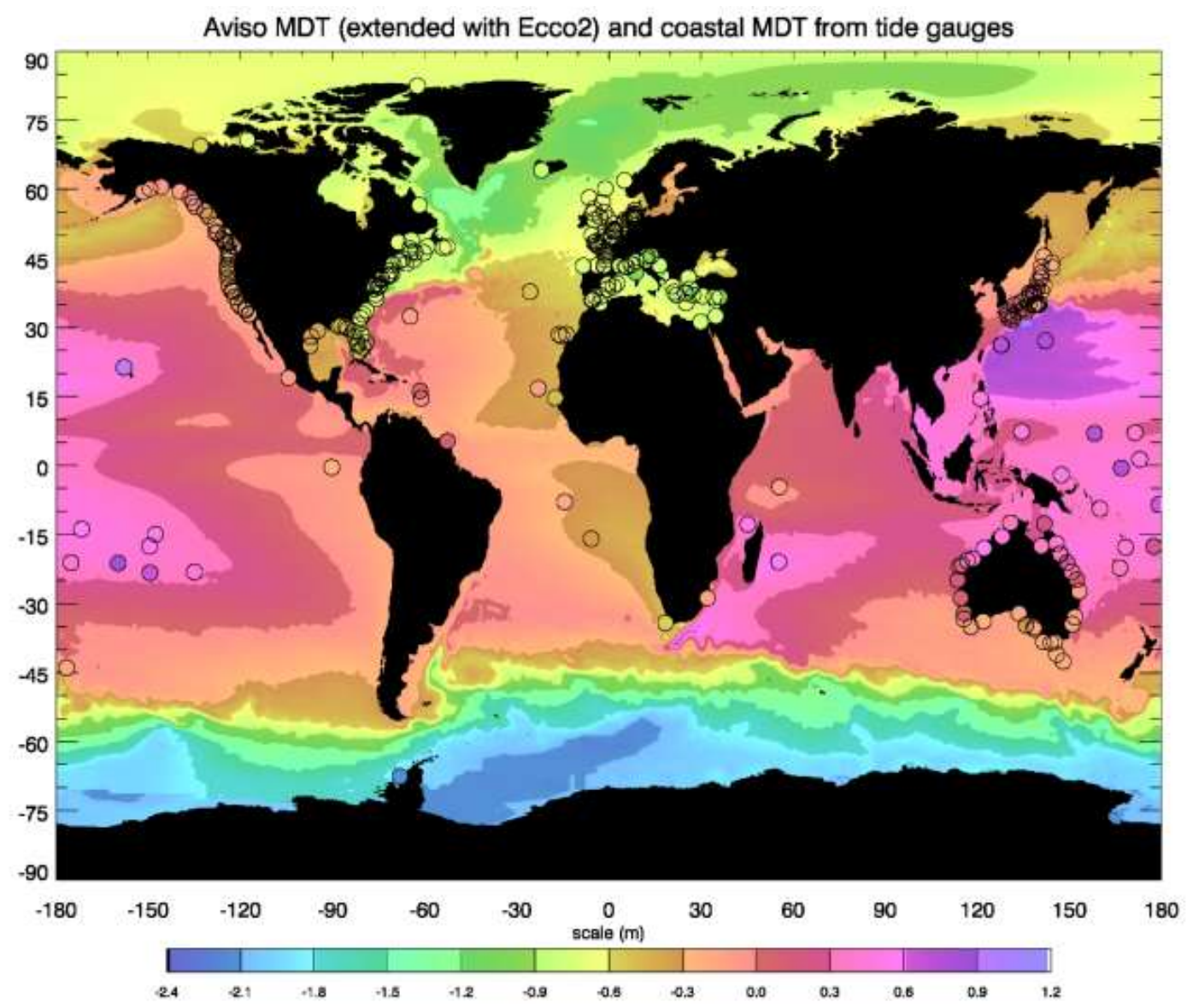

Figure 5: The spatial pattern of the Aviso MDT compared with the tide gauge MDT based on the EIGEN-6c4 geoid. Where the Aviso MDT has no data (mainly ice-covered regions), the Ecco2 model is shown instead.

The spatial distribution of the various MDT measurements can be seen from Figure 5. The map cannot show all details, however the general patterns are visible. We note that the MDT at the gauge on the east coast of South Africa (Richards Bay) agrees well with the Aviso global MDT, however the resolution of the thin strip of ocean to the west of the Agulhas current is crucial, as nearby ocean values are very different. More detailed examinations reveal similar results for the Gulf Stream, Kuroshio, and East Australian Current. 


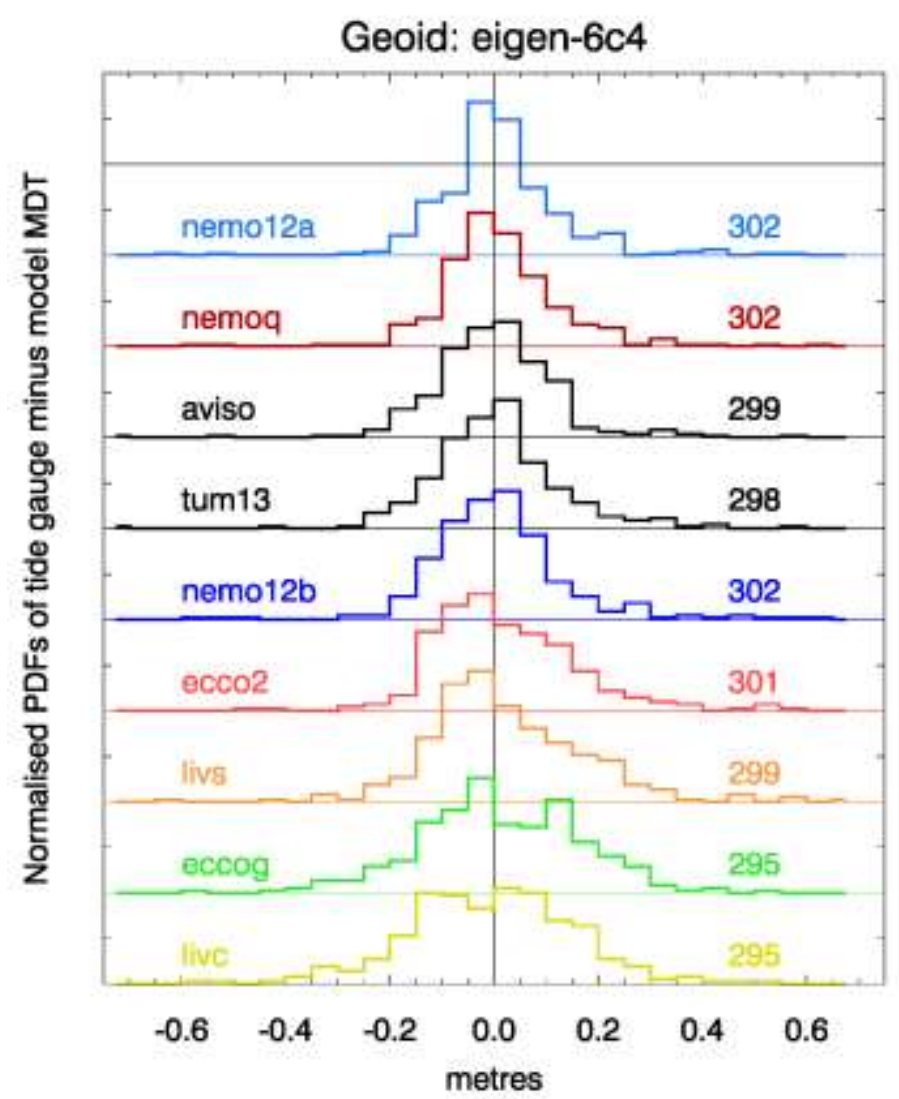

Figure 6: PDFs of the misfits between the tide gauge MDT using the EIGEN-6C4 geoid to its full resolution, and the various global products (median values subtracted). The PDFs are normalised relative to a Gaussian with the same standard deviation, and are offset by \pm 1 from their neighbours. Numbers to the right represent the number of available points for comparison in each case.

The distribution of misfits for these tide gauge values relative to the various global oceanographic MDT models is shown in Figure 6. A broader, more Gaussian distribution (peaks close to 1 with this normalization) are found with the coarse resolution models (livc,livs,eccog). It also illustrates the fact that the better comparisons (narrower distributions) have higher peaks than would be expected for a Gaussian distribution, consistent with the high kurtosis discussed above.

The PDFs in Figure 6 appear to have a longer positive tail than the associated negative tail. A long positive tail suggests that tide gauges are at positions, which are special in some way, leading to a systematic sign in the misfits, where they are large. We hypothesize that this is reflecting the fact that, being coastal, many tide gauges are close to the top of a steep continental slope, which produces a local geoid maximum at small length scales. In the absence of sufficient in situ gravity data, such maxima are likely to 
be reduced by smoothing, leading to the geoid product estimate being lower than the true geoid, and hence the MDT being higher than the true value.

With this interpretation, high kurtosis and a longer positive tail in the PDF would be diagnostic of an artificially smooth geoid. We can test this interpretation by calculating the statistics using various degrees of smoothing, produced by truncating the geoid at different resolutions. At the same time, this allows us to see the effect of resolution on the size of the misfit. The results are shown in Figure 7. The long positive tail and high kurtosis do occur when the geoid is poorly resolved, supporting our interpretation. The effect seems to peak at truncations of around degree 300-600, corresponding to length scales of about 40-70 km, but remains even with the full resolution geoid. We interpret this as being a measure of the missing in situ information limiting the resolution of the geoid in some places.

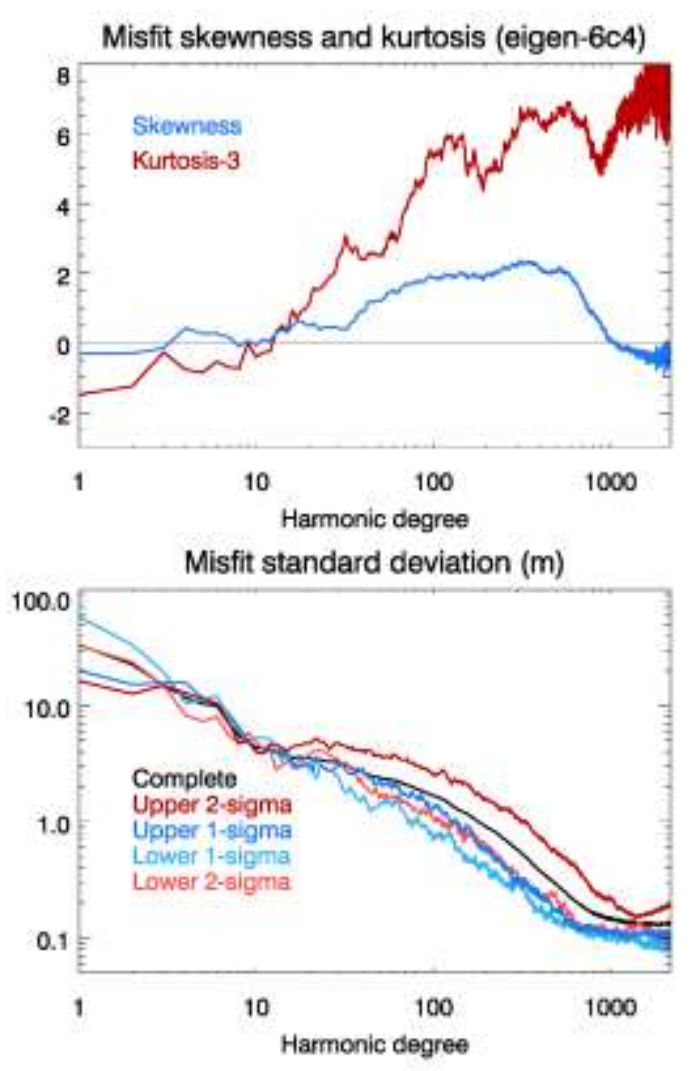

Figure 7: Statistics of misfit between Nemo12a and tide gauge MDTs using the EIGEN-6c4 geoid at different truncations. The standard deviation is shown based on the full PDF, or as the width of the PDF required to contain $34 \%$ of data below or above the median, or half the width containing $47.5 \%$ below or above the median. These would all be the same for a Gaussian distribution. 
The error standard deviation results show large and continuous improvements with increasing resolution, but begin to plateau at around degree 700, again suggestive of a limit to the added value of the in situ data. The values taken from different parts of the distribution are quite consistent (and lower than the overall standard deviation), apart from the value representative of the upper, more extreme values, confirming that the positive tail has the larger departure from a Gaussian distribution.

In an attempt to determine which are the best models and geoids to use, we rank the 27 possible comparisons of 9 global MDTs with 3 geoids, according to the size of the misfits. The global MDTs include the 7 ocean models described in the Methods section, plus two observational products: AVISO and TUM13.

The non-Gaussian nature of the PDFs means that no single statistic is representative of the distribution, so we use three different measures: standard deviation, width of the part of the PDF containing the central $68 \%$ of the data, and width of the part containing the central 95\%. The resultant rankings are shown in Figure 8. The three geoids are EIGEN-6C4 (Förste, 2014), GOCO05c (Fecher et al., 2017) and EGM2008 (Pavlis et al., 2012). The GOCO05c product was extended from its native resolution of degree 720 using EGM2008 coefficients at higher degrees All three geoids therefore include information up to degree 2190. 


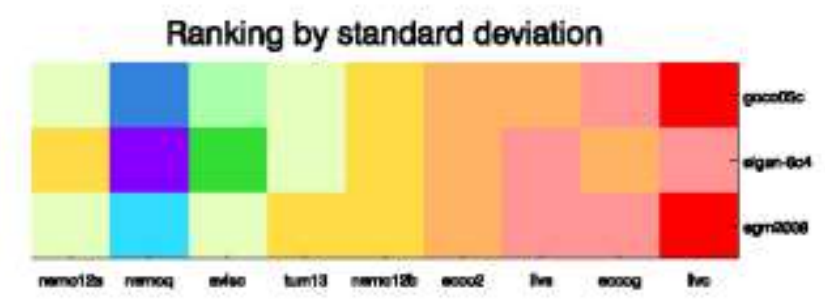

Ranking by $68 \%$ width

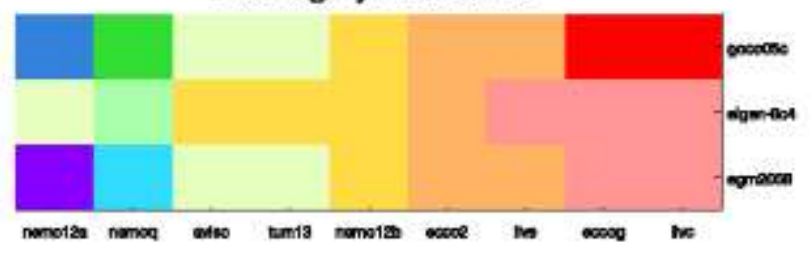

Ranking by $95 \%$ width

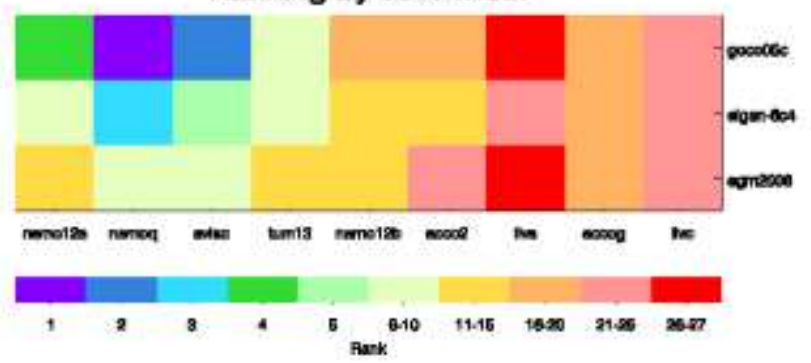

Figure 8: Ranking of quality of comparison of MDTs at tide gauges using three geoids, compared with 9 global products. Three different criteria are used as described in the text

The low-resolution ocean MDT models, LivC, EccoG and LivS, consistently perform poorly, and NemoQ, Aviso and Nemo12a consistently perform well, with TUM13 and Nemo12b in the middle, and Ecco2 closer to the poor end. It is perhaps to be expected that the "observational" products, Aviso and TUM13, should do well, being the most strongly constrained to the real ocean. It is also natural that TUM13 should be slightly worse, as it does not include any dynamical constraints, unlike AVISO. However, the ocean model results are interesting. The three low-resolution models perform almost equally poorly, despite assimilation of geodetic data into one of them (EccoG).

The ranking of geoids is less consistent (unsurprisingly given the importance of fine scale information which is derived from very similar, incomplete sources in all cases), with different geoids performing best under different ranking criteria.

Looking back at Table 1, the final column shows the percentage of comparisons which were within $9 \mathrm{~cm}$, after matching the medians. For a Gaussian distribution, this would be $68.2 \%$ if $9 \mathrm{~cm}$ represented one standard deviation. We can see from this that the best global MDTs have "typical" errors of around $9 \mathrm{~cm}$, if "typical" is defined as analogous 
to one standard deviation of a Gaussian distribution. This error is similar to the findings for Norway as presented by (Ophaug et al., 2015)

\section{GOCE++ combined Coastal MDT}

The satellite derived satellite MDT is generally less accurate in the coastal region due to the sparse coverage of valid altimetry observations. For a description of the satellite MDT se section 2. Due to the degradation in both MSS and geoid artifacts in the coastal region are typically seen as MDT contours crossing the coastline when plotting these. In the GOCE++ project we attempted to derive a coastal MDT by inserting MDT values over land and subsequently smoothing these into the ocean using an iterative spatial filter. The land values can be based on the tide gauge MDT values, the satellite based MDT in the coastal grid cells, or a combination of both.

\subsection{Land values}

In the tide gauge based solution the tide gauge MDT values are used to fill in the land values. This is done by linearly interpolating the MDT values from either tide gauges or from the MDT model in the coastal zone onto the entire grid of land cells.

In the satellite based solution the land value for a given coastal grid point is estimated as the average of the raw MDT grid values in a box centered on the coastal grid cell. The size of this box is by default chosen to be 9 times 9 grid points which approximately corresponds to a 1 times 1 degree box, as all grids for the test is at 1/8 degree resolution. Hence a local average (defined by the size of the box) for each coastal grid cell is used as a representation of the land value. It is important to notice that the altimetry based land values will not have the constraining effect provided by the tide gauge MDT values, but only provide an additional smoothing effect ensuring a less noisy MDT along the coast.

In the combined solution, coastlines without tide gauges are supplemented with altimetry based land values as described above. Subsequently the land values along the coast are simply interpolated to all land grid cells using linear or nearest neighbor interpolation. 


\subsection{Filtering}

To smooth the raw MDT values a spatial filter is applied. The filter is an average or box filter where the kernel is a $n x$ times $n y$ matrix, where $n x$ and $n y$ are the number of kernel points in the east-west and north-south direction, respectively. In the north-south direction, the size of the filter is fixed with a default value of two while it is scaled by the latitude in the east-west direction. The filter is iteratively applied over both land and ocean grid cells causing the simple average filter to converge toward a Gaussian filter. However, at each iteration, the land values are reset to their original value. This has the effect of maintaining the coastal values and increasing the smoothing in the coastal regions without affecting the open ocean. In general ten iterations are used.

\subsection{Software}

The methodology was implemented in the publically available software "coastMDT" which allows estimation of the coastal MDT in a given region (see the detailed description of the software and how to access it in Appendix 2). Figure 9 shows a flowchart of the software "coastMDT". The green boxes represent data input to the software; the purple boxes the functionality and the blue box the final product. The functionality can briefly be explained in the following steps:

- Step 0: The tide gauge data is references to the same ellipsoid as the altimetry data.

- Step 1: The raw gridded satellite and tide gauge MDTs are derived.

- Step 2: A region of interest is selected based on a longitude and latitude range.

- Step 3: Land values are estimated based on the methods described in sec. 4.1.

- Step 4: Filtering over both land and ocean grid cells is applied.

- Step 5: Plotting, error estimation, and saving of the final MDT. 


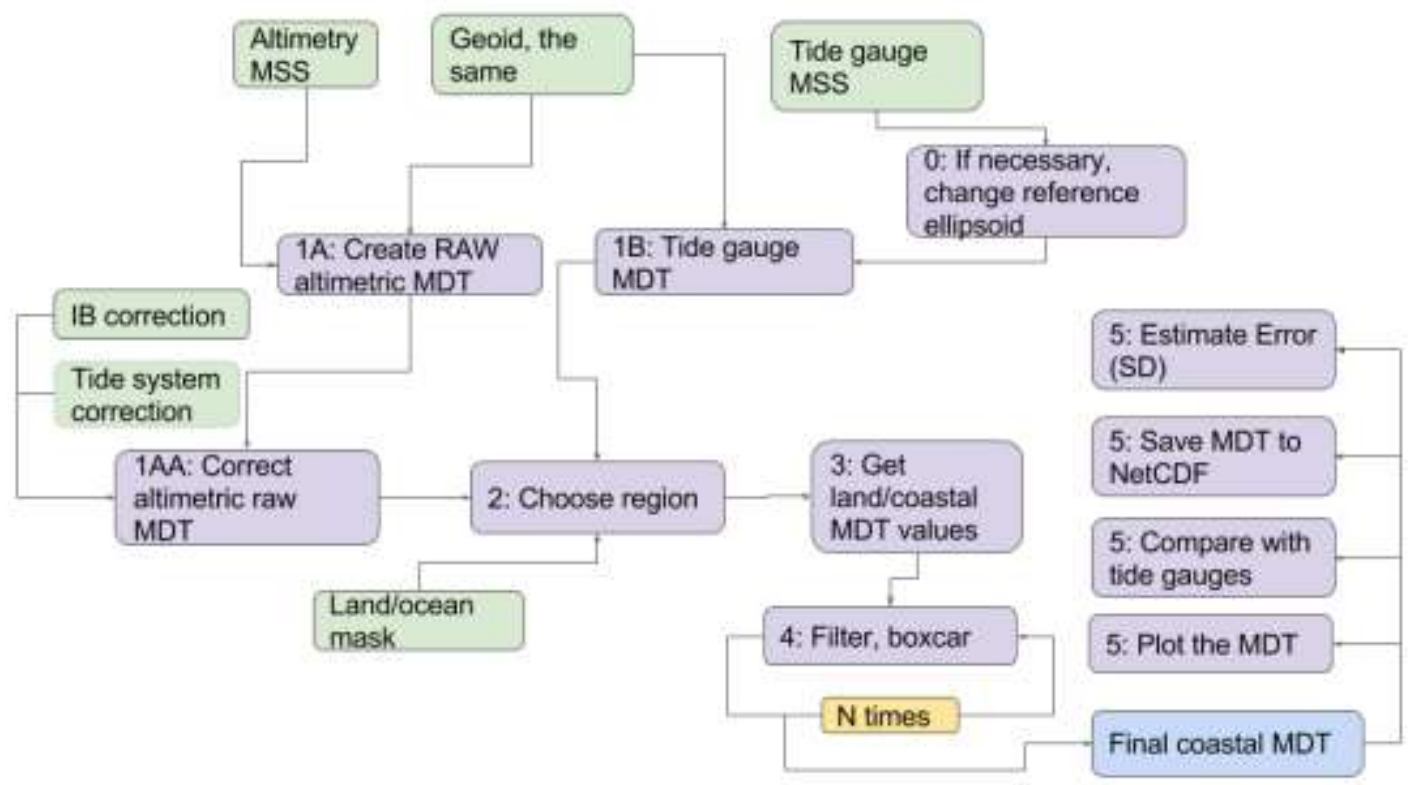

Figure 9: Flowchart of the software "coastMDT".

\section{Results}

\subsection{The GOCE++ Northeast Atlantic MDT model}

As a demonstration of the combined coastal MDT based on the GOCE++ approach the raw and filtered solutions are shown for the Northeast Atlantic coastline (Figure 10). The coastal values in the example are based on a combination of the tide gauge and altimetry as described above. The tide gauges used in this section all lie in the range of numbers 2 to 98 as used in Figures 3 and 4 and described in appendix 1.
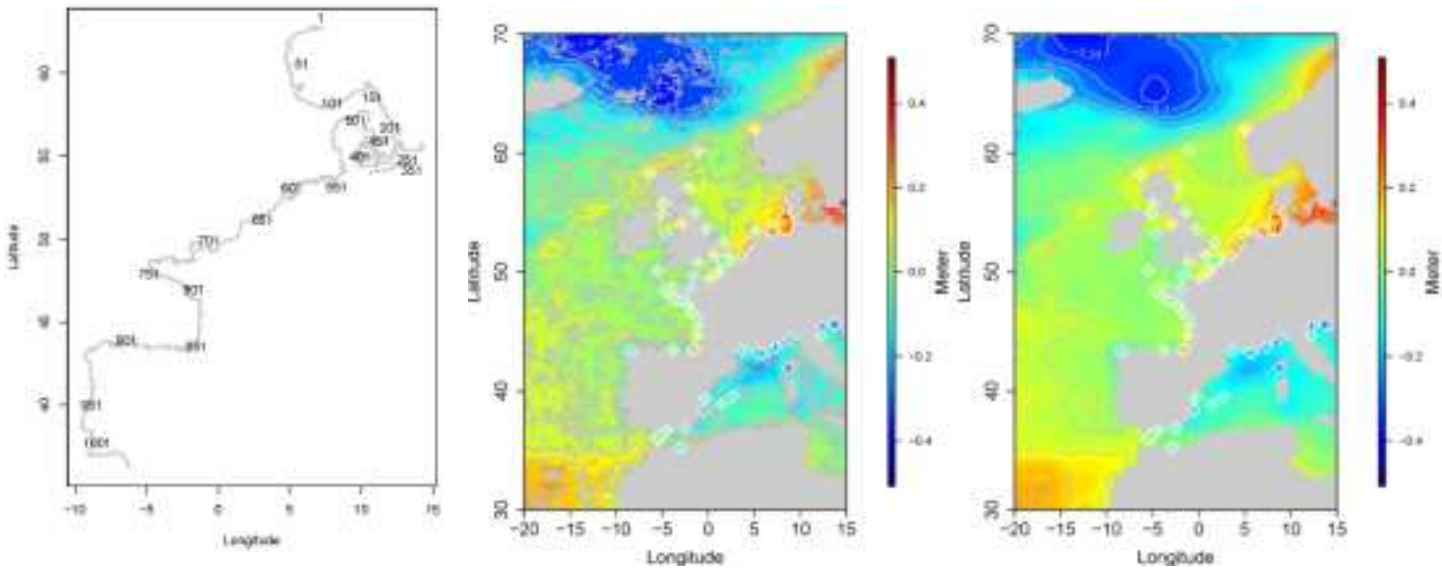

Figure 10: Northeast Atlantic tide gauges and MDT, Left the numbering of the grid points used for the evaluation of the GOCE++ model. Middle. An example of the raw MDT, right, the filtered MDT, where the 
land values are based on a combination of tide gauges and altimetry. The location of the tide gauges and the corresponding MDT value is shown with crosses.

Figure 11 displays the MDT solutions along the Northeast Atlantic coastline, from Norway to the southern tip of Spain following the labelling in Figure 10. The black curve is the unfiltered MDT corresponding to the raw DTU10MSS-EIGEN4C difference. The blue and red curves represent the coastal MDTs based on a combination of satellite altimetry and tide gauge MDT, and satellite altimetry only, respectively. For comparison, we have included the comparison to a typical satellite MDT. Here we used a MDT derived in the same way as the DTU13MDT (Knudsen et al., 2011) namely based on the satellite MDT values of MSS minus geoid filtered with a Gaussian filter with radius 0.7 degrees and with no land values (shown in green). There is no doubt, that the filtering improves the stability of the MDT solution and that the various filtered solutions generally agree. In some places there are deviations up to approximately 10 cm e.g. index 350-450, 500-650, and 800-900, which corresponds to the coastline along the inner Danish waters, the North Sea, and the Bay of Biscay. However, it is difficult to quantify the quality of the GOCE++ approach visually from this plot.

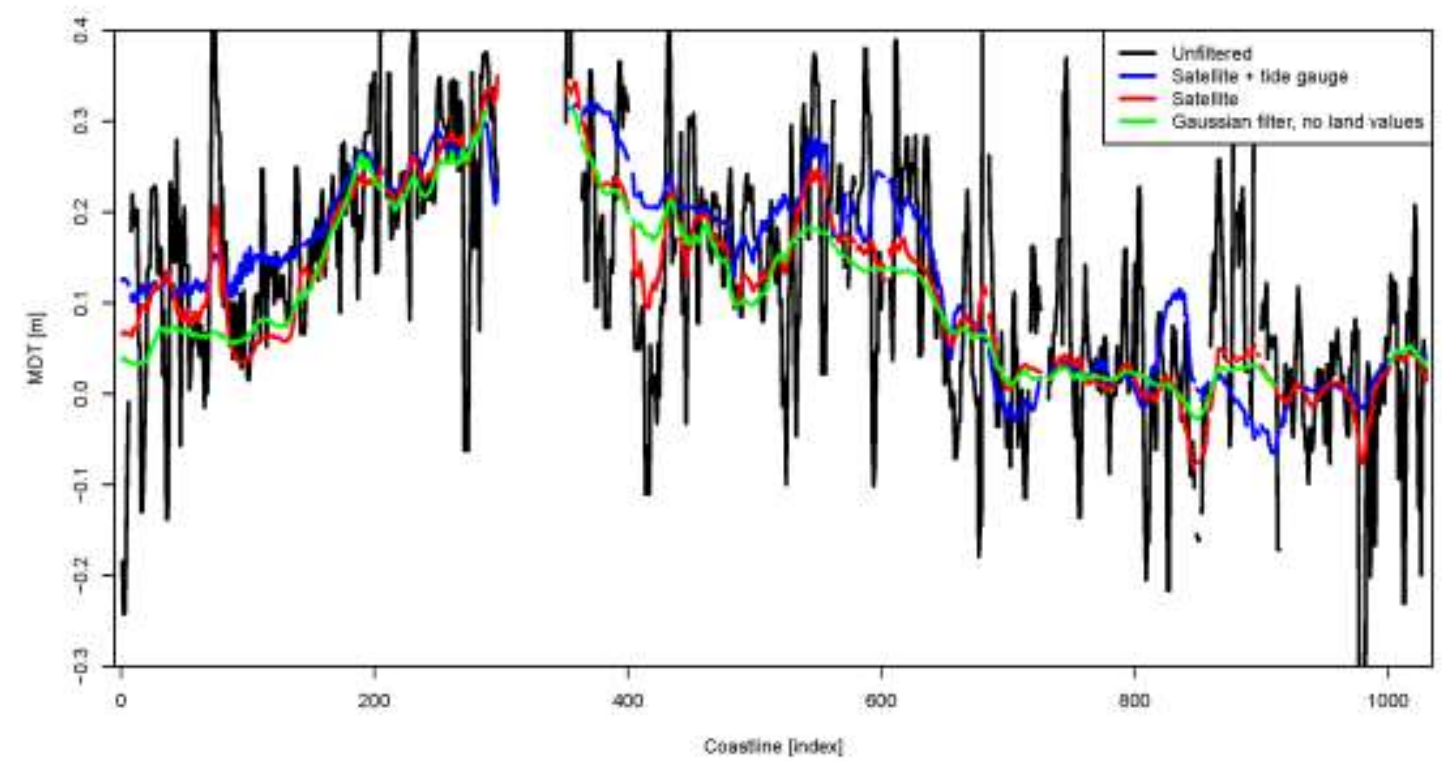

Figure 11: MDT solutions along the Northeast Atlantic. The black curve represents the unfiltered MDT, the blue curve represents the MDT solution where the land values are a combination of the satellite and tide gauge MDT values, the red curve represents the MDT solution where the land values are based on the unfiltered satellite MDT values, and the Green curve represents the MDT solution where a Gaussian filter and no land MDT values has been used. 
To evaluate the uncertainty of the MDT solution we apply a bootstrap approach. Since the individual grid points are correlated, we divide the raw MDT data set into blocks, which we assume are uncorrelated. We then create a large number $\mathrm{N}$ of artificial data sets by sampling with replacement among the different blocks. For each of the bootstrap data set we derive a filtered MDT solution. In this way, we get a distribution of solutions from which we can estimate the standard deviation of the MDT.

For the validation we select the tide gauges along the Danish, German and French coastlines as the representation of tide gauges is dense here (corresponding to coastal grid points labelled between 300 and 900 in Figure 10). To have independent data for the validation we randomly divide the tide gauges into two groups; $20 \%$ for validation and $80 \%$ which are used to derive the MDT solution. We can then estimate the RMSE as a measure for the quality of the different solutions. Since the result will depend on which of the tide gauges that are used to derive the solution, we repeat the exercise 100 times. This provides a distribution of the RMSE for the different solutions.

The RMSE distributions for the solutions are shown in Figure 12. In the solutions, land values have been from either altimetry or a combination of altimetry and tide gauges both have medians of $5.8 \mathrm{~cm}$. The MDT without land values filtered with a classical Gaussian filter of 0.7 degrees exhibits a median of $6.3 \mathrm{~cm}$. In this investigation we notice a clear improvement if we include land-based MDT values or not. However, we only see a marginal difference if we use satellite altimetry or a combination of satellite altimetry and tide gauge MDT as land values. 


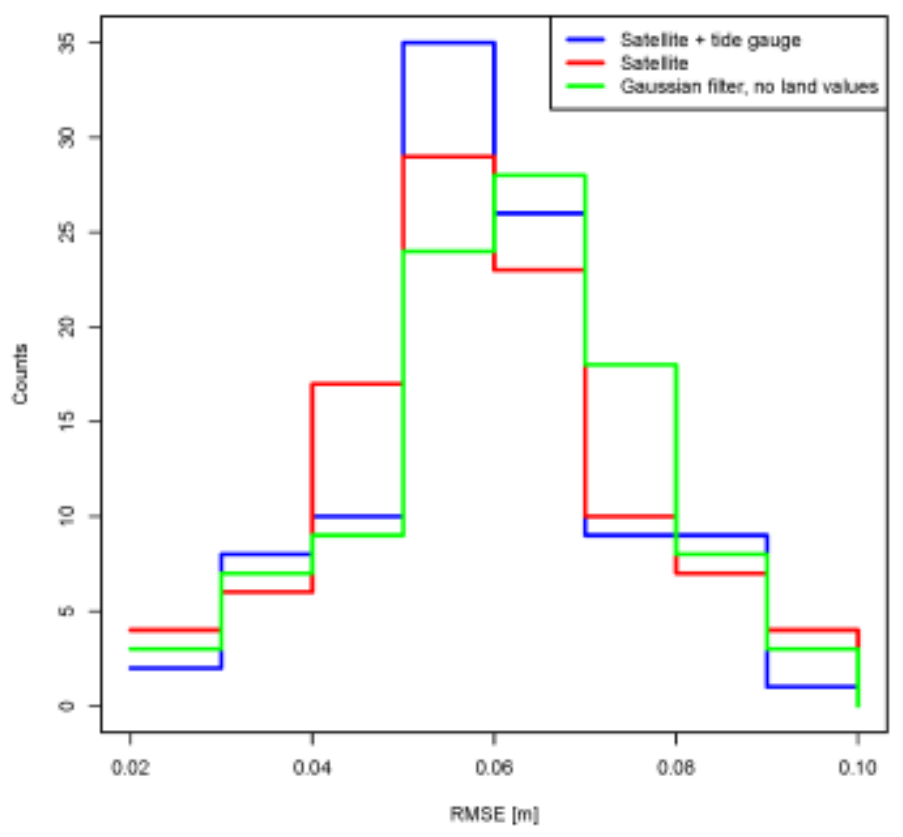

Figure 12: RMSE distributions for the MDT solutions; The MDT using combined tide gauge and satellite altimetry as land values are shown in blue. The MDT using satellite altimetry as land values is shown in red. The Gaussian filtered MDT without land values are shown in green.

\subsection{Cryosat-2 validation of GOCE++ MDT}

Currently SAR altimetry is becoming available with Cryosat- 2 and Sentinel-3A/3B to improve the mapping of the short scales in the MSS (Huang, 2017). Hence we evaluate the potential of using SAR altimetry in future geodetic MDT models as SAR altimetry has not been used for MSS computation. In the coastal zone, satellite altimeter data processed with SAR methodology provide water height observations of higher resolution and accuracy compared to the conventional pulse-limited altimeters (Dinardo et al., 2017). Hence, we expect that they should improve the estimation of the MDT in the coastal stripe within 100 kilometres from land. We assess the CryoSat-2 altimetry products over a time interval of 6-years from October 2010 to November 2017 along the North-eastern coasts of the Atlantic Ocean to quantify this.

The SAR data are from ESA Grid Processing on Demand (G-POD) processor enables processed with two different SAR retracking methodologies, called SAMOSA-2 (Ray et al., 2014) and SAMOSA+ (Dinardo et al., 2017). The second provides improved coastal data compared to the first, differences are both in the waveforms generation (Hamming weighting window on the burst data prior to the azimuth Fast Fourier Transform (FFT), 
zero-padding prior to the range FFT, doubling of the extension for the radar range swath) and in the retracking methodology. We use here SAMOSA+ and its corresponding Pseudo-LRM data, also called reduced SAR altimetry (RDSAR). This latter is generated by the TUDABo processor (http://wiki.services.eoportal.org/tikiindex.php?page $=\mathrm{G}-\mathrm{POD}+$ services) and retracked using the TU-Darmstadt Adaptive Leading Edge Sub-waveform retracker (TALES) and Spatio-Temporal Altimeter Waveform Retracking (STAR) sub-waveform retrackers (Roscher et al., 2017, Fenoglio and Buchhaupt, 2017). The quality of RDSAR and LRM data are comparable. LRM was disregarded near coast in the estimation of past MSS. The impact of the new SAMOSA+ data quality on the MDT estimation is seen from an estimate of a new MDT by averaging the 6 years of CryoSat- 2 data on a $0.25 \times 0.25$ degree grid. We then compare it to the reference geodetic MDT output of this project. The standard deviation of differences between the reference MDT surface and the MDT surfaces constructed from SAMOSA+, TALES and STAR open sea and coastal data are $6.7 \mathrm{~cm}$ for SAMOSA,$+ 8.5 \mathrm{~cm}$ for TALES and $6.9 \mathrm{~cm}$ for STAR respectively. The largest difference between the reference MDT and the new MDT surfaces is in the coastal zone. Figure 13 shows the difference between the reference MDT and the new MDT surfaces. The best agreement with the reference MDT (smallest differences in the German Bight) is obtained using the SAMOSA+ data (Figure 13, left) followed by the RDSAR STAR data, while with RDSAR TALES the agreement is lower.
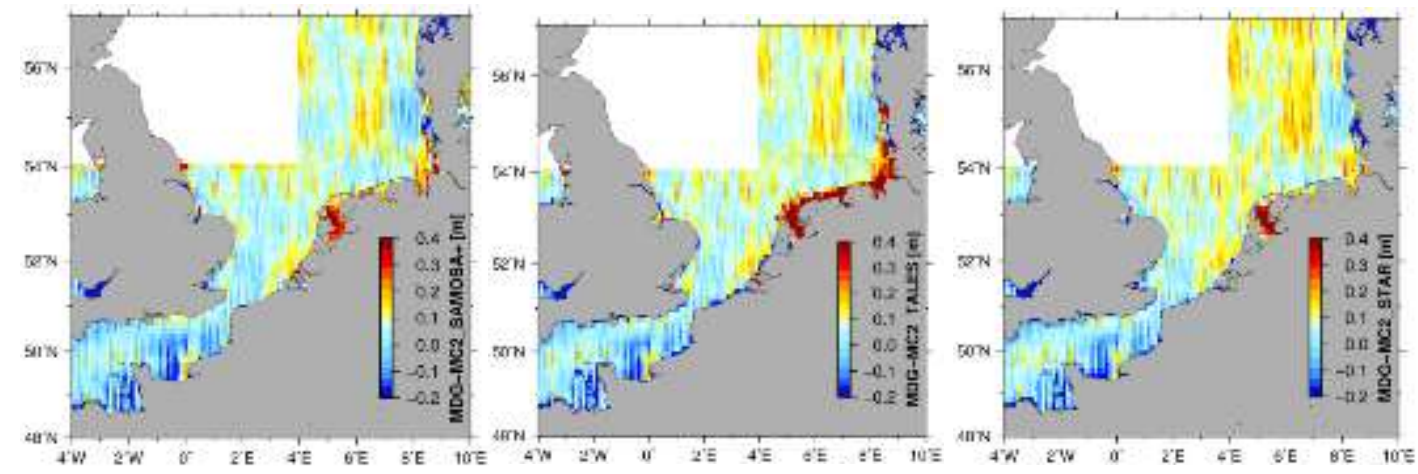

Figure. 13. Difference between the GOCE++ MDT and the MDT derived from the three SAR altimetry datasets: SAMOSA+; RDSAR (STAR and TALES) datasets. 


\section{Discussion, recommendations and conclusion}

In the GOCE++ project we have tested a new approach to improve the MDT in the coastal zone, where the solution is based on both satellite altimetry and tide gauge data. The tide gauge MDT values are integrated into the geodetic MDT by inserting these as land values and subsequently using an iterative average filter to smooth the tide gauge MDT values into the altimetry based MDT. The approach was evaluated for the Northeast Atlantic coast where a dense representation of tide gauges is present. A validation of the coastal MDT was conducted by comparing the solution to that obtained from tide gauges. To ensure independent data for the validation only $80 \%$ of the tide gauges were included in the MDT solution. The new approach showed a small but clear improvement in terms of RMSE compared to the classical spatial Gaussian filter.

In this investigation, the land values were assigned using linear interpolation, which is not optimal when the tide gauges are unevenly distributed along the coastline or if the distance between them is large (see the heterogeneous distribution of the tide gauges on Figure 2). An improved future approach could be to consider the correlation pattern potentially from ocean model MDTs when interpolating the land values. The GOCE++ approach to derive a coastal MDT based on altimetry and tide gauge data was implemented as an R package "coastMDT" which is freely available for further research. The package can be used with the provided test data used here or with data provided by the user.

The typical misfit between tide gauge and satellite or oceanographic MDT was found to be around $9 \mathrm{~cm}$. This misfit was found to be mainly due to small scale geoid errors. Similarly, a single tide gauge places only weak constraints on the coastal dynamic topography, especially when the non-Gaussian nature of the errors means that much larger misfits are possible. Optimal use of the tide gauges thus relies on exploiting the coherence of the MDT along the coast, together with a good quantification of errors in the tide gauge values. Preliminary analyses have shown that sea level variations at tide gauges bear very different relationships to nearby open ocean values from satellite altimetry, depending on the site considered.

Where variability at gauges agrees with open ocean altimetry, it seems safe to assume that the tide gauge mean should also reflect the ocean mean dynamic topography. Where it does not, there are three possibilities: the data quality may be poor, the local geoid error may be large, or local coastal processes may be important. Possible 
processes are wave setup and low salinity intrusions due to freshwater input from rivers, both of which have been suggested to contribute tens of centimeters in places. In fact, some gauges are far enough up rivers that they may reflect river flow more directly. Altimetry closer to the coast would help to distinguish between these possibilities.

Improved mapping of coastal currents and short scale geoid signals will be important to improve coastal MDT. This can be done through the integration with very highresolution ocean model. Local analysis into the Norwegian MDT demonstrated the value of SAR altimetry in mapping local coastal topographies from CryoSat-2 (Idžanović et al, 2017). Along the Norwegian coast strong levelling ties between tide gauges permit a comparison, which is not dependent on direct GPS measurements at each gauge. The addition of measurements very close to the coast was found to help in avoiding errors due to coastal currents, seen in both the satellite data and ocean model. The remaining error, however, was found to be dominated by small-scale geoid error, which can only be addressed by local gravity measurements.

Similar investigations into Australian coastal MDT also highlighted the small-scale geoid error, at larger amplitude in this case, with sporadic mismatches of 0.1-0.2 m (Filmer et al., 2018). In some cases, these were found to be in regions of complex coastal geometry (in one case the gauge is some distance from the coast). In this investigation, we found that addition of CryoSat-2 data had the potential to improve the coastal resolution. In this case, however, another issue was also identified: the availability of tide model data was found to be a limiting factor, which was overcome by switching from the GOT4.8 to the FES2012 tidal model. This highlights the importance of reassessing altimeter correction models as new, more-coastal data become available.

The biggest challenge for unified calculation of a coastal and global MDT is clearly the lack of small-scale geoid information for comparison with point measurements from tide gauges. This is a problem with varying geographical impact, which will ultimately only be overcome by use of local measurements; either of gravity in a region surrounding the point in question, or of geopotential at the point (see later).

A second challenge is the limited number of tide gauges with GPS ties (Woodworth et al., 2017). We have identified 302 such gauges in this project, in comparison to 1007 datum-controlled records, which overlap the satellite altimetry era (1993 onwards). The 
vertical velocity of the GNSS station used was known for only 141 of these 302 tide gauges (47\%), the epoch of the height for only 160 (53\%). Thus, for a significant number of the selected tide gauges, it was not possible to propagate the height at the chosen epoch 2005.5. Actually, 90\% of the 400 coastal (closer than $20 \mathrm{~km}$ ) ULR6 vertical velocities being in absolute value below $3.5 \mathrm{~mm} /$ year, it can be assumed that the maximum error of an ellipsoidal height at an unknown epoch with an unknown velocity is around $4 \mathrm{~cm}$ if we consider that this unknown epoch is between 1995.0 and 2017.0 (and so distant to a maximum period of 11.5 years from the chosen period 2005.5). Even without additional data, the present investigations have highlighted a number of ways in which immediate progress can be made based on observations, which are currently available or will become available in the next few years.

The accuracy of the tide gauge location can also have an impact on the MDT value through the geoid value extraction. The locations used in this study were taken from the PSMSL and SONEL databanks which strives to locate the tide gauges as accurate as possible. To estimate the impact of possible remaining errors in the locations of the tide gauges used, a geoid slope map has been computed over a global $40 \mathrm{~km}$ wide coastal strip from the EGM2008 model (Pavlis et al., 2012). The histogram on Figure 14 shows a median equal to $0.014 \mathrm{~m} / \mathrm{km}$.

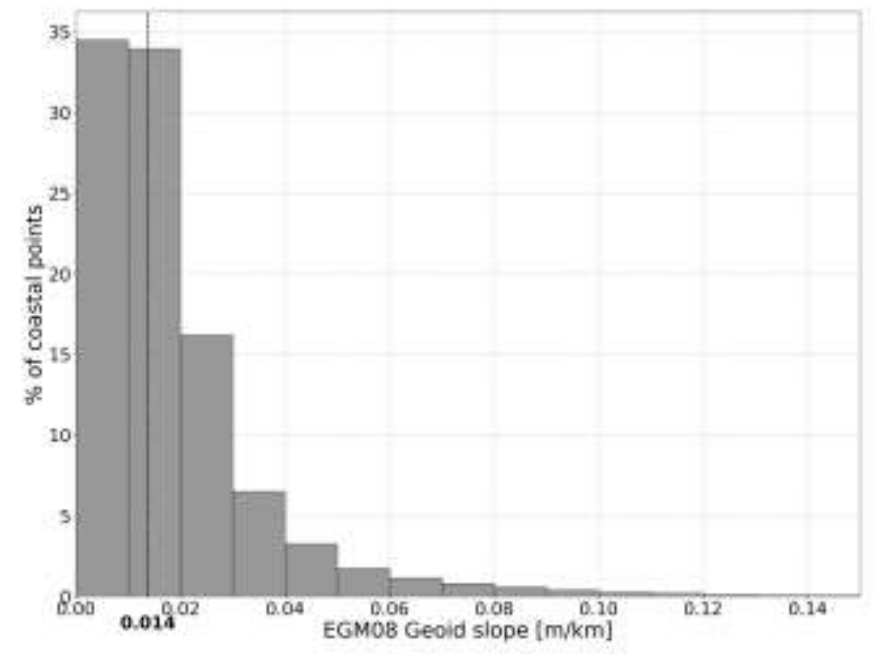

Figure 14: Histogram of the geoid slopes in coastal areas

A number of recommendations for future directions on both short-term horizon of a few years, and a longer-term decadal time scale can be found from the GOCE++ results at (http://gocehsu.eu). The recommendations detail our view on how to use and our 
strategies to improved GNSS coverage at tide including strategies to account for local vertical land movement when computing tide-gauge MDT.

The strategies for deriving an optimal MDT will play out very differently in different regions. In well-surveyed regions with many tide gauges, the tide gauge data is likely to play a significant role in constraining the coastal solutions. In poorly-surveyed regions, where tide gauge data are sparse, there will be no along-coast averaging effect, and the sporadic measurements with correspondingly large errors (given the lack of information about short length-scale variability) are unlikely to make a significant contribution. As an example, the Pacific island measurements appear to have both random and systematic errors of order $0.1 \mathrm{~m}$. On the other hand, model data show that the MDT remains within $0.02 \mathrm{~m}$ of the coastal MDT out to distances of hundreds of kilometres from most islands meaning that the satellite data will produce the greater constraint. In order for isolated tide gauges to make a significant contribution, it is crucial that local geoid information be improved, and the improvement be quantified.

\section{Acknowledgement.}

The authors are thankful to Phil Woodworth for valuable suggestions. The authors acknowledge the support to the ESA STSE GOCE ++ DYCOT project via ESA contract No 4000114331//15/NL/FF/gp. They also acknowledge the SONEL (http://www.sonel.org) and RENAG (http://webrenag.unice.fr) services for providing GPS data and geodetic ties at tide gauges. Hongyang Lin, Mick Filmer, Marc Véronneau are warmly thanked for providing geodetic ties respectively in Japan and USA, Australia and Canada.

\section{References}

Altamimi, Z., X. Collilieux, and L. Métivier (2011), ITRF2008: An improved solution of the International Terrestrial Reference Frame, J. Geod., 85, 457-473.

Amjadiparvar, B., Rangelova, E. V., Sideris, M. G. \& Véronneau, M. (2013) North American height datums and their offsets: The effect of GOCE omission errors and systematic levelling effects. $\mathrm{J}$ Appl Geodesy, 7(1), 39-50, DOI: 10.1515/jag-2012-0034

Andersen, Ole Baltazar, Knudsen, Per, Stenseng, Lars (2016) The DTU13 MSS (Mean Sea Surface) and MDT (Mean Dynamic Topography) from 20 Years of Satellite Altimetry. IAG Symposia, pages: 1-10, 2016, Springer Verlag 
Andersen O. B and P. Knudsen (2009) The DNSC08 mean sea surface and mean dynamic topography. J. Geophys. Res., 114, C11, doi:10.1029/2008JC005179

Bingham, R. J., and K. Haines (2006) Mean dynamic topography: Intercomparisons and errors, Philos. Trans. R. Soc. A, 364(1841), 903-916, doi:10.1098/rsta.2006.1745.

Bingham, R.J. Knudsen, P., Andersen, O. B. Pail, R. (2011) An initial estimate of the North Atlantic steady-state geostrophic circulation from GOCE, Geop Res Lett (ISSN: 0094-8276) (DOI: http://dx.doi.org/10.1029/2010GL045633), vol: 38, issue: 1, pages: L01606.

Dinardo, S., Fenoglio-Marc, L., Buchhaupt, C., Becker, M., Scharroo, R., Fernandez, J., Benveniste, J. (2017). Coastal SAR and PLRM Altimetry in German Bight and Western Baltic Sea, Advance in Space Research, Special Issue CryoSat-2, doi.org/10.1016/j.asr.2017.12.018.

Ekman, M. (1989), Impacts of geodynamic phenomena on systems for height and gravity, Bull. Geod., 63, 281-296,doi:10.1007/BF02520477.

Featherstone, W. E., and M. S. Filmer (2012), The north-south tilt in the Australian Height Datum is explained by the ocean's mean dynamic topography, J. Geophys. Res., 117, C08035, doi:10.1029/2012JC007974.

Fecher T, Pail R, Gruber T (2015) Global gravity field modeling based on GOCE and complementary gravity data. Int J Appl Earth Obs Geoinf 35(A):120-127. doi: 10.1016/j.jag.2013.10.005.

Fecher, T., Pail, R., Gruber, T. et al. (2017) GOCO05c: A New Combined Gravity Field Model Based on Full Normal Equations and Regionally Varying Weighting Surv Geophys (2017) 38: 571. https://doi.org/10.1007/s10712-016-9406-y

.Fenoglio-Marc, L., Buchhaupt C. (2017). TUDaBo SAR-RDSAR for G-POD, Altimetry Coastal and Open Ocean Performance, Algorithm Theoretical Basis Document (ATBD), SAR-RDSAR for GPOD, EOEP-SEOM-EOPS-TN-17-046, Issue: 1.3

Filmer, M. E., C. W. Hughes, P. L. Woodworth, W. E. Featherstone and R. J. Bingham (2018), Comparison of oceanographically and geodetically derived ocean mean dynamic topography at Australian tide gauges. J. Geodesy. doi: 10.1007/s00190-018-1131-5.

Foerste, C. (2014). EIGEN-6C4: the latest combined global gravity field model including GOCE data up to degree and order 1949 of GFZ Potsdam and GRGS Toulouse. EGU General Assembly Conference Abstracts. 16.

Gerlach, C. \& Rummel, R. (2013) Global height system unification with GOCE: A simulation study on the indirect bias term in the GBVP approach. Journal of Geodesy, 87(1), 57-67 DOI: 10.1007/s00190-012-0579-y

Gruber, T., Gerlach, C. \& Haagmans, R. H. N. (2012) Intercontinental height datum connection with GOCE and GPS-levelling data. Journal of Geodetic Science, 2(4), 270-280 DOI: 10.2478/v10156-012-0001-y

Holgate, S. J., A. Matthews, P. L. Woodworth, L. J. Rickards, M. E. Tamisiea, E. Bradshaw, P. R. Foden, K. M. Gordon, S. Jevrejeva, and J. Pugh (2013), New data systems and products at the Permanent Service for Mean Sea Level, J. Coast. Res., 29, 493-504.

Huang, J. (2017). Determining coastal mean dynamic topography by geodetic methods. Geophys. Res. Lett, 44, 11,125-11,128, https://doi.org/10.1002/2017GL076020 
Idžanović, M., V. Ophaug and O. B. Andersen (2017), The coastal mean dynamic topography in Norway observed by CryoSat-2 and GOCE. Geophys. Res. Lett. 44, 5609-5617, doi:10.1002/2017GL073777

IERS (2010), IERS Conventions (2010), G. Petit and B. Ludzum (Eds.), International Earth Rotation Service Technical Note, 36, 179 pp., isbn:3-89888-989-6.

Knudsen, Per, Bingham, R., Andersen, Ole Baltazar, Rio, Marie-Helene (2011) A global mean dynamic topography and ocean circulation estimation using a preliminary GOCE gravity model Journal of Geodesy (ISSN: 0949-7714) (DOI: http://dx.doi.org/10.1007/s00190-011-0485-8), vol: 85, issue: 11 , pages: $861-879$

Köhl, A., Stammer, D., Cornuelle, B., (2007): Interannual to decadal changes in the ECCO global synthesis, J. Phys. Oceanogr., 37, 313-337, doi: 10.1175/JPO3014.1

Lin, H., K. R. Thompson, J. Huang, and M. Véronneau (2015), Tilt of mean sea level along the Pacific coasts of North America and Japan, J. Geophys. Res. Oceans, 120, 6815-6828, doi:10.1002/2015JC010920.

Madec, G. (2008), NEMO ocean engine, Note du Pole de modelisation, vol. 27, pp. 1288-1619, Inst. Pierre-Simon Laplace, Paris, France

Marshall J., C. Hill, L. Perelman, and A. Adcroft (1997a) Hydrostatic, quasi-hydrostatic, and nonhydrostatic ocean modelling, J. Geophys. Res., 102, 5733-5752, doi:10.1029/96JC02776.

Marshall J., A. Adcroft, C. Hill, L. Perelman, and C. Heisey (1997b) A finite-volume, incompressible Navier Stokes model for studies of the ocean on parallel computers, J. Geophys. Res., 102, 5753-5766, doi:10.1029/96JC02775.

Menemenlis, D., Fukumori, I., and Lee, T., (2005a) Using Green's functions to calibrate an ocean general circulation model, Mon. Weather Rev., 133, 1224-1240, doi:10.1175/MWR2912.1.

Menemenlis, D., C. Hill, A. Adcroft, J. -M. Campin, B. Cheng, B. Ciotti, I. Fukumori, P. Heimback, C. Henze, A. Köhl, T. Lee, D. Stammer, J. Taft and J. Zhang, (2005b) NASA Supercomputer Improves Prospects for Ocean Climate Research. EOS 86 (9), 89-96. doi: 10.1029/2005EO090002.

Ophaug, V., K. Breili, C. Gerlach (2015) A comparative assessment of coastal mean dynamic topography in Norway by geodetic and ocean approaches, J. Geophys Res: Oceans, 120, 12

Pavlis, N. K., S. A. Holmes, S. C. Kenyon, and J. K. Factor (2012) The development and evaluation of the Earth Gravitational Model 2008 (EGM2008), J. Geophys. Res., 117, B04406, doi:10.1029/2011JB008916.

Ray,C., C. Martin-Puig, M.P. Clarizia, G. Ruffini, S. Dinardo, C. Gommenginger, J. Benveniste (2014) SAR altimeter backscattered waveform model, IEEE Trans. Geosci. Remote Sens., vol. 53, no. 2, pp. 911-919,

Roscher, R., Uebbing, B., Kusche, J. (2017) STAR: Spatio-temporal altimeter waveform retracking using sparse representation and conditional random fields. Remote Sensing of Environment, 201, pp.148-164, doi.org/10.1016/j.rse.2017.07.024.

Rummel, R. (2012) Height unification using GOCE. Journal of Geodetic Science, 2(4), 355-362, DOI: $10.2478 / \mathrm{v} 10156-011-0047-2$ 
Sanchez-Reales, J. M., Andersen, O. B., Vigo, M. I (2016) Improving Surface Geostrophic Current from a GOCE-Derived Mean Dynamic Topography Using Edge-Enhancing Diffusion Filtering. Pure and Applied Geophysics (ISSN: 0033-4553) (DOI: http://dx.doi.org/10.1007/s00024-015-10509), vol: 173, issue: 3 , pages: $871-884$

Santamaría-Gómez A., Gravelle M., Dangendorf S., Marcos M., Spada G., Wöppelmann G. (2017), Uncertainty of the 20th century sea-level rise due to vertical land motion errors. Earth and Planetary Science Letters, 473, 24-32.

Smith, D. M., and J. M. Murphy (2007) An objective ocean temperature and salinity analysis using covariances from a global climate model, J. Geophys. Res., 112, C02022, doi:10.1029/2005JC003172.

Ophaug, V., K. Breili, C. Gerlach (2015) A comparative assessment of coastal mean dynamic topography in Norway by geodetic and ocean approaches, J. Geophys Res: Oceans, 120, 12

Woodworth P.L., C.W. Hughes, R.J. Bingham, T. Gruber (2013). Towards worldwide height system unification using ocean information. Journal of Geodetic Science, 2(4), 302-318.

Woodworth, P. L., M. Gravelle, M. Marcos, G. Woppelmann, and C. W. Hughes (2015). The status of measurement of the Mediterranean mean dynamic topography by geodetic techniques, J. Geod., 89, 1-17, doi:10.1007/s00190-015-0817-1.

Woodworth, P. L., Wöppelmann G., Marcos M., Gravelle M., and Bingley R. M. (2017), Why we must tie satellite positioning to tide gauge data, Eos, 98, doi:10.1029/2017E0064037

Wöppelmann, G., and M. Marcos (2016), Vertical land motion as a key to understanding sea level change and variability, Rev. Geophys., 54, 64-92, doi:10.1002/2015RG000502.

Wunsch, C., and D. Stammer (1997). Atmospheric loading and the oceanic "inverted barometer" effect, Rev. Geophys., 35, 79-107, doi: 10.1029/96RG030337. 


\section{Appendix 1.}

Tide gauge locations

The locations of the 302 tide gauges used in this study, showing the numbering scheme used in the various plots within the article. The solid circles represent the first tide gauge in each colour.

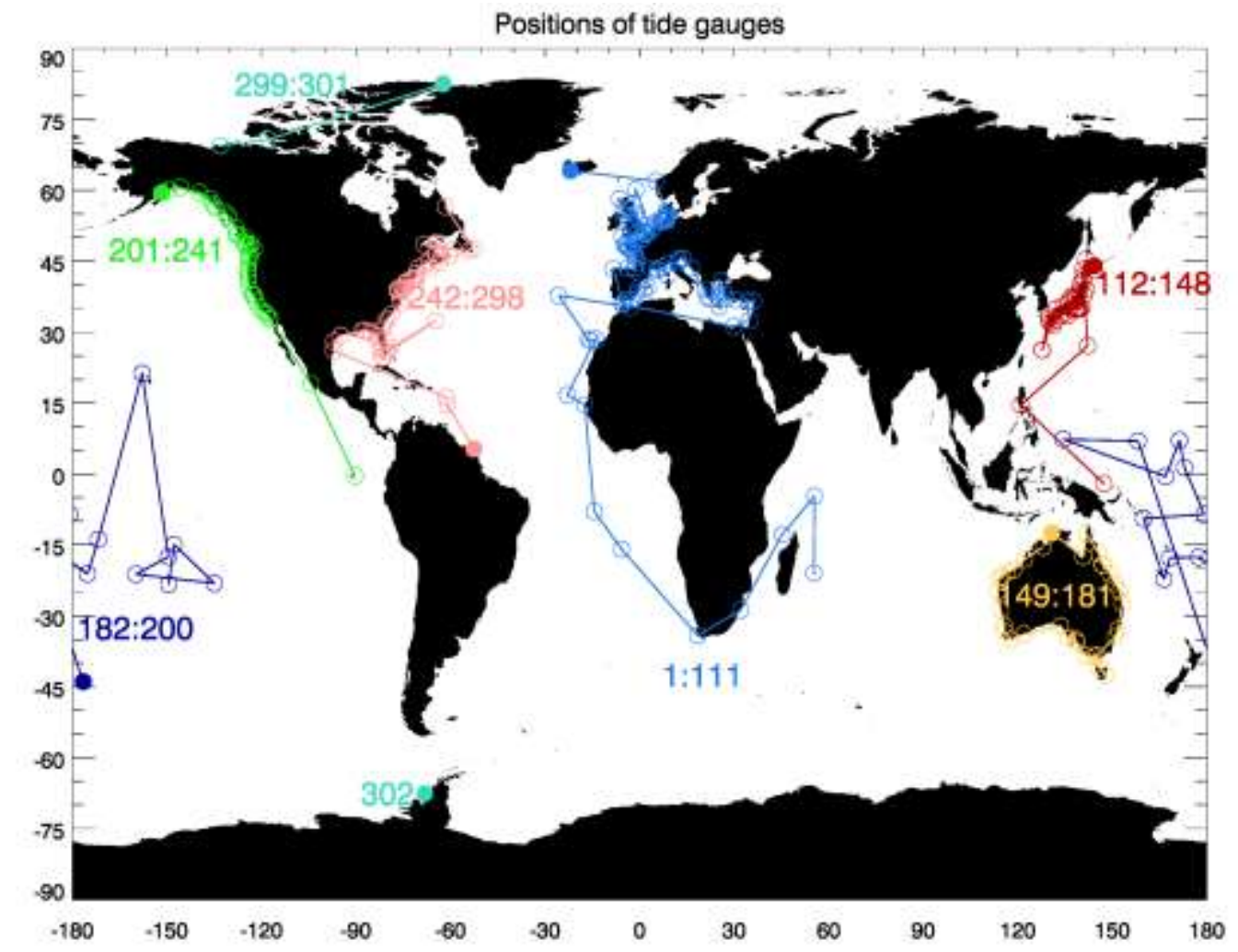

Figure A1: Positions of tide gauges used in this study, showing the numbering scheme used in plots. The solid circles represent the first tide gauge in each colour.

Appendix 2.

\section{Software}

The methodology described in the previous sections was implemented in a software package "coastMDT" written in the open source language "R". The software is freely available from GitHub (https://github.com/cavios/coastMDT) including installation instructions and documentation.

The package "coastMDT" offers the user the possibility to derive a geodetic MDT for a selected region of interest. In relation to the package a collection of data sets 
is also available including the MSS/MDT values at the tide gauge stations for the combined GOCO05C (Fecher et al., 2017) and EIGEN 6C4 geoids (Förste 2014) as well as the DTU $10 \& 15 \mathrm{MSS}$ (Andersen et al., 2016). The gridded datasets are all given with a resolution of a 1/8 x 1/8 degree. A detailed description of the functions in the package is found in the CoastMDT user manual and complete example of how to use the package to derive the MDT is described in the coastMDT tutorial. 